\title{
Higher Prevalence of Metabolic Syndrome in Child-adolescent Patients with Bipolar Disorder
}

\author{
Satyajit Mohite ${ }^{1,2}$, Hanjing $\mathrm{Wu}^{1,2}$, Shiva Sharma ${ }^{1}$, Luca Lavagnino ${ }^{1,2}$, Cristian P. Zeni ${ }^{1,2}$, Terrence T. Currie ${ }^{1}$, \\ Jair C. Soares ${ }^{1,2}$, Teresa A. Pigott ${ }^{1,2}$ \\ ${ }^{1}$ The University of Texas Harris County Psychiatric Center, Houston, TX, ${ }^{2}$ Department of Psychiatry and Behavioral Sciences, The University \\ of Texas Health Science Center, Houston, TX, USA
}

\begin{abstract}
Objective: Previous studies have indicated a convergent and bidirectional relationship between metabolic syndrome (MetS) and bipolar disorder (BD). As most of these studies focused mainly on adults diagnosed with BD, our study aims to investigate and characterize metabolic disturbances in child-adolescents diagnosed with BD.

Methods: We retrospectively examined the medical records of psychiatric hospitalizations with admitting diagnosis of $\mathrm{BD}$ in child-adolescents (age < 18 years). Body mass index (BMI), lipid profile, fasting blood glucose, and blood pressure were primary variables. National Cholesterol Education Program criteria were used to define MetS. Reference group data was obtained from the National Health and Nutrition Examination Survey study. Statistical analyses included $t$ tests, chi-square tests, and Fisher's exact tests.

Results: We identified 140 child-adolescent patients with BD (mean age $=15.12 \pm 1.70$ years, 53\% male). MetS was significantly more common in BD compared to the reference group: 14\% (95\% confidence interval [95\% Cl] 8-20) vs. $6.7 \%(95 \% \mathrm{Cl} 4.1-9.2), p=0.001$ with no significant difference by sex. MetS components were higher in the BD group, particularly BMI $\geq 95 \%(25 \%$ vs. $11.8 \%, p<0.001)$ and high blood pressure $(17 \%$ vs. $8 \%, p=0.05)$. Moreover, female patients had lower odds of high blood pressure (odds ratio $=0.24[95 \% \mathrm{Cl} 0.08-0.69], p=0.005$ ) . Conclusion: Compared with the general child-adolescent population, the prevalence of MetS was significantly higher in patients with BD of same age. This reiterates the notion of an increased risk of MetS in patients diagnosed with $\mathrm{BD}$; and thus, further exploration is warranted.
\end{abstract}

KEY WORDS: Bipolar disorder; Metabolic syndrome; Child-adolescents; Body mass index; Lipids; Blood glucose.

\section{INTRODUCTION}

Bipolar disorder (BD) is a chronic and debilitating disorder associated with recurring episodes of (hypo-) mania and/or depression and is diagnosed based on the severity of symptoms [1]. The international prevalence rate was noted to be $1.8 \%$ (95\% confidence interval $[95 \% \mathrm{Cl}$, $1.1 \%-3.0 \%$ ) [2]. Per the National Comorbidity Survey Adolescent Supplement data, American adolescents (age $13-18$ years) have a $2.9 \%$ lifetime prevalence of bipolar

Received: November 22, 2019 / Revised: January 8, 2020 Accepted: February 7, 2020

Address for correspondence: Satyajit Mohite

Department of Psychiatry and Behavioral Sciences, The University of Texas Health Science Center, 1941 East Rd, Houston, TX 77054, USA

E-mail: Satyajit.S.Mohite@uth.tmc.edu

ORCID: https://orcid.org/0000-0002-2873-3025 disorder, with $2.6 \%$ experiencing severe impairment [3]. However, under-reporting and misdiagnosis of BD has been noted in adolescents BD [4]. BD can drastically impair functioning in adolescents due to cognitive impairment in their formative years [5-7].

An estimated $4 \%$ of adolescents in the United States (US) meet criteria for metabolic syndrome (MetS); based on an age modified definition of the Adult Treatment Panel (ATP) III criteria established for adults [8]. MetS was reported highly prevalent $(16.7 \%-67 \%)$ among patients with BD worldwide [9-11]. Metabolic abnormalities are a major clinical concern due to their relationship with psychiatric outcomes [12]. Specifically, obesity and MetS have routinely been linked to BD [12]. Reviews by Taylor and MacQueen [13], Fagiolini et al. [14] addressed the common pathophysiological link between BD and MetS through several mechanisms, namely-dysregulations in

(ㄷ) This is an Open-Access article distributed under the terms of the Creative Commons Attribution Non-Commercial License (http://creativecommons.org/licenses/by-nc/4.0) which permits unrestricted non-commercial use, distribution, and reproduction in any medium, provided the original work is properly cited. 
glucose, insulin, hemostasis, sympathetic nervous system, and disturbances in the hypothalamic-pituitary-adrenal and the hypothalamic-pituitary-thyroid axes. Genetic studies have further contributed to the understanding of this association between BD and MetS through interconnected genes $[15,16]$. In the light of such recent evidences, the link between $\mathrm{BD}$ and metabolic abnormalities has been postulated to be bidirectional [17].

Moreover, studies have demonstrated a higher prevalence of manic and depressive symptoms in the setting of metabolic disturbances as well as poor medication compliance and lower functional outcome [18]. A cohort study on a population of adolescents diagnosed with $\mathrm{BD}$ reported an increased prevalence of obesity, type 2 diabetes mellitus, endocrine abnormalities and cardiovascular disorders [19]. This study also reported a significant association between adolescent-onset BD and pre-existing obesity, hypertension and endocrine disorders, postulating that MetS precedes early-onset BD [19]. Additionally, studies have found differences in MetS prevalence by sex in the patients with BD; including increased waist circumference in women and increased triglycerides (TG) in men [20-22]. To the best of our knowledge, there is a lack of literature examining any individual and combined metabolic disturbances in youth diagnosed with $\mathrm{BD}$, or any sex differences within this age group.

Our study aims to review the prevalence of metabolic syndrome and its individual components (i.e., body mass index [BMI], lipid profile, fasting blood glucose, and blood pressure) in a sample of children and adolescent patients ( $<18$ years) with $\mathrm{BD}$; and to compare our findings with reference group data from the National Health and Nutrition Examination Survey (NHANES) study for under age 18 individuals without $\mathrm{BD}$.

\section{METHODS}

This study employed a cross-sectional design. After acquiring Institutional Review Board (IRB) approval (IRB No. HSC-MS-16-0746) and de-identified data consent waiver, data was retrospectively obtained from records of patients (age $<18$ years) admitted to the University of Texas Health Harris County Psychiatric Center between January 2010 and December 2015. Records were de-identified and then uploaded to a secure, confidential server prior to data analysis. Inclusion criteria included: (i) age $<18$ years, (ii) discharge diagnosis of bipolar I disorder, bipolar II disorder and bipolar disorder not otherwise specified (NOS) based on Diagnostic and Statistical Manual of Mental Disorders, 4th Edition (DSM-IV) criteria, determined by the assessing psychiatrist, and (iii) inpatient hospitalization between January 2010 and December 2015. Patients who were not fasting at least 10 hours before blood drawn were excluded.

In addition to demographic information, age of onset, prior hospitalization history, previous psychotropic medication history, and discharge psychotropic medications regimen were identified. Family psychiatric history was gathered from patient interviews and obtained collateral information. Blood samples were drawn within 24 hours of admission in a fasting state, before starting any medications. Systolic and diastolic blood pressures, tobacco smoking status, height, weight, fasting serum glucose and lipid panel including total cholesterol, high-density lipoprotein (HDL), and TG were retrieved for metabolic disturbance assessment.

Blood pressures were manually measured and recorded by trained medical staff using age-appropriate cuff sizes with auscultation at time of admission. BMI was calculated by the electronic medical record after trained staff members entered manually measured heights and weights at the time of admission. National Cholesterol Education Program (NCEP) ATP III-modified criteria was used for MetS diagnosis [23], and at least 3 out of the 5 following components were required for diagnosis of MetS: (i) TG $\geq 150 \mathrm{mg} / \mathrm{dl}$, (ii) $\mathrm{HDL} \leq$ $40 \mathrm{mg} / \mathrm{dl}$ in men and $\leq 50 \mathrm{mg} / \mathrm{dl}$ in women, (iii) blood pressure $\geq 130 / 85 \mathrm{mmHg}$, (iv) fasting blood glucose $\geq 110$ $\mathrm{mg} / \mathrm{dl}$, and (v) BMl $\geq 28.8 \mathrm{~kg} / \mathrm{m}^{2}$ [23]. We used equivalent BMI parameters instead of the waist circumference $(>102$ $\mathrm{cm}$ in men and $>88 \mathrm{~cm}$ in women) [23,24]. Reference group data was obtained from the findings of the NHANES 1999 - 2000 dataset [25-27]. Data was analyzed using SPSS 20 for Windows (IBM Co., Armonk, NY, USA) [28]. A univariate statistical analysis was performed with calculation of means and standard deviations (SD). Normality assumptions were verified using the Kolmogorov - Smirnov test, with application of $95 \% \mathrm{Cl}$. Bivariate statistical analyses were conducted on all study variables, with presence or absence of MetS as the dependent variable. Quantitative variable comparisons were performed using the student's $t$ test. Qualitative variable comparisons were performed using the chi-square test and Fisher's exact tests (for $\mathrm{n}<5$ ). 


\section{RESULTS}

\section{Sociodemographic and Clinical Characteristics of the Study Population}

One hundred forty patients diagnosed with BD were identified ([age $15.12 \pm 1.7$ years, average \pm SD]; 53\% males; $52 \%$ African-American, 39\% Caucasian). The predominant diagnosis was Bipolar NOS (95.71\%) In comparison, the reference group was comprised of younger age (9.22 \pm 5.93 years) and predominant Hispanic population (46.8\%) as seen in Table 1. The groups were not statistically significant from each other for sexes; but were significantly different by age and race/ethnicity.

\section{Individual Components of MetS in Study Population}

Patients diagnosed with BD had mean BMl: $26.12 \pm$

Table 1. Sociodemographic and clinical characteristics of study and reference groups

\begin{tabular}{lccc}
\hline \multicolumn{1}{c}{ Parameter } & $\begin{array}{c}\text { Patients with } \\
\text { BD }(\mathrm{n}=140)\end{array}$ & $\begin{array}{c}\text { Controls } \\
(\mathrm{n}=4,804)\end{array}$ & $p$ value \\
\hline Age (yr) & $15.12 \pm 1.7$ & $9.22 \pm 5.93$ & 0.000 \\
Sex, male (\%) & 53 & 51.5 & 0.909 \\
Race/Ethnicity & & & 0.000 \\
$\quad$ White & $54(39)$ & $1,092(22.7)$ & \\
African-American & $73(52)$ & $1,260(26.2)$ & \\
Hispanic & $11(8)$ & $2,246(46.8)$ & \\
$\quad$ Other/unknown & $2(1)$ & $206(4.3)$ & \\
Diagnosis (DSM-IV) & & & \\
$\quad$ Bipolar I & $2(1.43)$ & - & \\
$\quad$ Bipolar II & $4(2.86)$ & - & \\
$\quad$ Bipolar NOS & $134(95.71)$ & - & \\
\hline
\end{tabular}

Values are presented as or mean \pm standard deviation or number (\%). BD, bipolar disorder; DSM-IV, the Diagnostic and Statistical Manual of Mental Disorders 4th edition; NOS, not otherwise specified.
$6.73 \mathrm{~kg} / \mathrm{m}^{2}$, mean systolic blood pressure: $120.12 \pm 12.50$ $\mathrm{mmHg}$, mean diastolic pressure: $73.99 \pm 8.86 \mathrm{mmHg}$, mean serum glucose: $89.22 \pm 14.35 \mathrm{mg} / \mathrm{dl}$, mean serum triglycerides: $104.66 \pm 87.15 \mathrm{mg} / \mathrm{dl}$, and mean $\mathrm{HDL}$ : $48.82 \pm 12.78 \mathrm{mg} / \mathrm{dl}$ (Table 2).

Patients with $\geq 1$ Met $S$ components had a positive psychiatric family history $(67 \%)$, were diagnosed with the following: comorbid conduct disorder $(42 \%)$ and cannabis use disorder (42\%), and history of following psychotropic medication use: antipsychotics $(83 \%)$, valproic acid $(67 \%)$, and antidepressants ( $42 \%)$.

\section{Prevalence of Individual Risk Factors of MetS in Study Population and Comparison with Normal Healthy Controls}

When assessed for MetS individual criteria, $25 \%$ of patients with $\mathrm{BD}$ had $\mathrm{BMI} \geq 95$ th percentile, $13 \%$ had TG $\geq$ $150 \mathrm{mg} / \mathrm{dl}, 24 \%$ had $\mathrm{HDL} \leq 40 \mathrm{mg} / \mathrm{dl}$ in males or $\leq 50$ $\mathrm{mg} / \mathrm{dl}$ in females, $17 \%$ had systolic blood pressure (SBP) $\geq$ $130 \mathrm{mmHg}$ and/or diastolic blood pressure (DBP) $\geq 85$ $\mathrm{mmHg}$. Nine percent of patients diagnosed with BD had fasting blood glucose $\geq 110 \mathrm{mg} / \mathrm{dl}$ (Table 3).

Table 2. Individual components of MetS in study population

\begin{tabular}{lc}
\hline \multicolumn{1}{c}{ Parameter } & BD cases $(\mathrm{n}=140)$ \\
\hline Body mass index 95th percentile & $26.12 \pm 6.73$ \\
Systolic blood pressure $(\mathrm{mmHg})$ & $120.12 \pm 12.50$ \\
Diastolic blood pressure $(\mathrm{mmHg})$ & $73.99 \pm 8.86$ \\
Serum glucose $(\mathrm{mg} / \mathrm{dl})$ & $89.22 \pm 14.35$ \\
Triglycerides $(\mathrm{mg} / \mathrm{dl})$ & $104.66 \pm 87.15$ \\
HDL-C $(\mathrm{mg} / \mathrm{dl})$ & $48.82 \pm 12.78$ \\
\hline
\end{tabular}

Values are presented as mean \pm standard deviation.

MetS, metabolic syndrome; BD, bipolar disorder; HDL-C, high-density lipoprotein-C.

Table 3. Prevalence of individual risk factors of metabolic syndrome among patients with BD vs. reference group

\begin{tabular}{|c|c|c|c|c|c|c|c|c|}
\hline \multirow{2}{*}{ Variables of MetS } & \multicolumn{3}{|c|}{ Bipolar disorder $(n=140)$} & \multicolumn{3}{|c|}{ Reference group $(n=991)$} & \multirow{2}{*}{ OR $(95 \% \mathrm{Cl})$} & \multirow{2}{*}{$p$ value } \\
\hline & Female & Male & Total & Female & Male & Total & & \\
\hline BMI 95th percentile & 25 & 25 & $35(25)$ & 11.6 & 12.1 & $117(11.8)$ & $2.49(1.62-3.82)$ & $<0.001^{*}$ \\
\hline SBP and/or DBP (mmHg) & 7 & 26 & $18(17)$ & 5.1 & 10.8 & $79(8)$ & $1.82(1.05-3.13)$ & $0.05^{*}$ \\
\hline Serum glucose (mg/dl) & 12 & 7 & $13(9)$ & 5.3 & 10 & $75(7.6)$ & $1.25(0.67-2.32)$ & 0.48 \\
\hline Triglycerides (mg/dl) & 12 & 14 & $18(13)$ & 20.9 & 25.5 & $230(23.2)$ & $0.49(0.29-0.81)$ & $0.005^{*}$ \\
\hline HDL-C (mg/dl) & 25 & 23 & $34(24)$ & 19.3 & 27.3 & $230(23.4)$ & $1.06(0.7-1.6)$ & 0.77 \\
\hline Metabolic syndrome & 12 & 16 & $20(14)$ & 3.8 & 9.6 & $66(6.7)$ & $2.33(1.37-4.0)$ & $0.001 *$ \\
\hline
\end{tabular}

Values are presented as percent only or number $(\%)$.

$\mathrm{BD}$, bipolar disorder; $\mathrm{OR}$, odds ratio; $\mathrm{Cl}$, confidence interval; $\mathrm{BMI}$, body mass index; $\mathrm{SBP}$, systolic blood pressure; $\mathrm{DBP}$, diastolic blood pressure; HDL-C, high-density lipoprotein-C.

An asterisk indicates the significant difference ( $p \leq 0.05)$. 


\section{BMI}

When comparing BMI of the study and reference groups, the study sample had a significantly higher percentage with BMI $\geq 95$ th percentile ( $25 \%$ vs. $11.8 \%$, respectively) (odds ratio $[\mathrm{OR}]=2.49$ [95\% Cl 1.62-3.82], $p<0.001)$. This correlation remained consistent between sexes in the study sample: males ( $25 \%$ vs. $12.1 \%$ ) and females (25\% vs. $11.6 \%)$.

\section{Systolic and/or diastolic blood pressure}

Twenty six percent of males (vs. 10.8\% in the reference group) and $7 \%$ of females (vs. $5.1 \%$ in the reference group) in the study group met MetS criteria by blood pressure alone. Patients with BD had higher systolic and/or DBP than controls (17\% vs. $8 \%)(\mathrm{OR}=1.82[95 \% \mathrm{Cl} 1.05-$ 3.13], $p<0.05)$.

\section{Serum glucose}

No significant statistical difference in percentage fasting serum glucose $\geq 110 \mathrm{mg} / \mathrm{dl}$ was found between the study and reference groups $(\mathrm{OR}=1.25[95 \% \mathrm{Cl} 0.67-$ 2.32], $p=0.48$ ).

\section{Lipids}

Surprisingly, a lower percentage of patients with BD had increased triglycerides compared to controls (13\% vs. $23.2 \%)(\mathrm{OR}=0.49$ [95\% Cl 0.29-0.81], $p=0.005)$. The difference in percentages between the study and reference groups was even greater when comparing sexes: males (14\% vs. $25.5 \%$ ) and females (12\% vs. $20.9 \%)$. No significant statistical difference of HDL was observed between the study and reference groups $(\mathrm{OR}=1.06[95 \% \mathrm{Cl}$ $0.7-1.6], p=0.77)$.

\section{Combined MetS criteria}

Considering all individual components, patients diagnosed with BD had a higher prevalence of MetS than healthy controls (14\% vs. $6.7 \%$ ) even when accounting for differences in sex: males (16\% vs. $9.6 \%$ ) and females (12\% vs. $3.8 \%)$. The study group had significantly higher odds of having MetS compared to the reference group $(\mathrm{OR}=2.33$ [95\% Cl 1.37-4.0], $p=0.001)$.

\section{Prevalence of MetS, Individual MetS Components, and Sex Differences in BD Patients}

In the study group, $14 \%$ of patients with BD met diag-
Table 4. Prevalence of metabolic syndrome and its individual components by sex within patients with $\mathrm{BD}$

\begin{tabular}{lccll}
\hline \multicolumn{1}{c}{ Variables of MetS } & Female & Male & \multicolumn{1}{c}{ OR $(95 \% \mathrm{Cl})$} & $p$ value \\
\hline BMI 95th percentile & $17(25)$ & $18(25)$ & $1.09(0.51-2.35)$ & 0.82 \\
Hypertriglyceridemia & $8(12)$ & $10(14)$ & $0.89(0.33-2.41)$ & 0.82 \\
Low HDL & $17(25)$ & $17(23)$ & $1.18(0.54-2.55)$ & 0.67 \\
High blood pressure & $5(7)$ & $19(26)$ & $0.24(0.08-0.69)$ & $0.005^{*}$ \\
High fasting glucose & $8(12)$ & $5(7)$ & $1.92(0.6-6.2)$ & 0.27 \\
$\begin{array}{l}\text { MetS (three or more } \\
\text { criteria) }\end{array}$ & $8(12)$ & $12(16)$ & $1.38(0.53-3.6)$ & 0.63 \\
\hline
\end{tabular}

Values are presented as number (\%).

$\mathrm{BD}$, bipolar disorder; $\mathrm{BMI}$, body mass index; $\mathrm{HDL}$, high-density lipoprotein; MetS, metabolic syndrome; OR, odds ratio.

An asterisk indicates the significant difference $(p \leq 0.05)$.

nostic criteria for MetS. The mean age of patients with MetS was $14.73 \pm 1.55$ years and MetS prevalence was highest in Whites $(n=10,19 \%$ of all White patients with $\mathrm{BD})$. In the group with BD also diagnosed with MetS, females were less likely to have high blood pressure $(\mathrm{OR}=$ 0.24 [95\% Cl 0.08-0.69], $p=0.005)$. The remaining individual MetS components and the combination of MetS components were not significant different between sexes $(p>0.05)$ (Table 4).

\section{DISCUSSION}

Our study demonstrated that patients with BD met MetS criteria more often than healthy controls through BMI and SBP and/or DBP; as well combined MetS components. A strong correlation exists between MetS with in adults with BD $[11,29,30]$, however there is a paucity of studies on MetS in children and adolescents diagnosed with BD. To the best of our knowledge, our study is a distinctive one to directly examine the prevalence of MetS and its individual subcomponents in this patient population.

A previous study addressed BMI in BD patients of age 717 years [31], and reported that $16.5 \%$ patients had BMI $\geq$ 95th percentile, while $25 \%$ patients in our study met such BMI criteria. In contrast to their predominantly nonCaucasian BD patients with high BMI [31], our study sample meeting MetS diagnostic criteria were predominantly White. Our findings align with another study that reported $64.7 \%$ adolescents with BD had $\geq 1$ MetS component, mainly elevated TG and DBP [32]. Naiberg's study sample had higher TG levels than their controls, but in contrast we found significantly lower TG levels in our patients 
with $\mathrm{BD}$ in comparison to our controls. This variability could be attributed to patients' diets, as TG levels are known to be affected by fasting status [33]. It also raises the possibility of the involvement of another unknown mechanism, as both the study and NHANES reference groups were assessed with an overnight fasting [26]. Previously MetS components were thought to precede BD [19]. If true, MetS demands more attention in the context BD management for better prognosis.

Genetics may play a crucial role as a positive family history of MetS, especially high blood pressure and serum glucose, is associated with a 1.5 relative risk of developing MetS in patients with BD [34,35]. Our study found $67 \%$ of patients with BD and MetS had a positive family psychiatric history, but family history for MetS or its components was unavailable. The risk for developing MetS or its components in young patients with BD may differ by sex as a study reported females (mean age $12.6 \pm 3.6$ years) had larger waist circumference and higher BMI, TG, LDL and total cholesterol, but had lower systolic blood pressure and fasting blood glucose than males (mean age $12.5 \pm 3.5$ years). After 6.6 years of follow-up in this study, females (mean age $16.6 \pm 5.4$ years) continued to have larger waist circumference, higher $\mathrm{BMI}$ and higher TG. Additionally, females had higher SBP and DBP and fasting blood glucose than males (mean age $16.0 \pm$ 5.6 years) [36]. Our study did not find a significant difference in all MetS components between sexes in patients with BD, except female patients with BD showed a significantly lower frequency of high blood pressure.

Different theories seek to explain the relationship between metabolic abnormalities and BD. Patients diagnosed with BD show increased levels of inflammatory markers and altered steroid hormone concentrations and inflammation is associated with BMI and mood symptom severity $[37,38]$. Obesity is further exacerbated by poor dietary habits and an altered lifestyle $[39,40]$. Binge eating and emotionally driven eating behavior are highly prevalent in adolescent populations with BD $[12,41]$.

Many psychotropic medications used in the treatment of BD have been linked with metabolic abnormalities [42]. Certain atypical antipsychotics (e.g., Olanzapine, Risperidone) prescribed as monotherapy or in combination with other psychotropics such as mood stabilizers, have been found to cause weight gain, metabolic abnormalities, and increased cardiovascular risk in adolescents
[43-48]. In contrast, another study reported a high prevalence of obesity and metabolic syndrome in medication-naïve patients [49]. The patients in our study were on psychotropic medications: antipsychotics (83\%), valproic acid (67\%), and antidepressants (42\%) treatment. These medications exhibit a propensity to increase specifically BMI in adolescents with BD [50]. Although these psychotropics significantly impact MetS profile, this can be ameliorated through cautious medication selection based on careful therapeutic risk-benefit analysis. Several studies have scrutinized the safety data for antipsychotics in younger aged populations and have postulated a few recommendations [51-54]. Quetiapine, Ziprasidone, Aripiprazole, and Paliperidone were comparatively found to have a less-severe impact on the MetS profile $[43,55,56]$. Our study also found the presence of MetS in patients with BD who were not on medications (13\%). These divergent findings suggest metabolic abnormalities could be an inherent part of the BD disease process [57].

Our study is noteworthy because the adolescent population diagnosed with BD has not been well explored. Additional study strengths include comparison with a national reference group, MetS assessment via based on the NCEP individual and combined component criteria. Although this study was effective in assessing the differences between adolescent BD with patients and controls in setting of MetS and its associated components, it had certain limitations. Chart review yielded some significant variables especially comorbid conduct disorder and cannabis use disorder, family psychiatric history, and psychotropic medication history, but the overall analysis lacked some vital clinic information including history of self-harm and suicidality, duration and severity of the illness, and average length of hospitalization. The cross-sectional study design is limiting because the predictability and the temporal relationship between BD and MetS in younger aged patients cannot be assessed. Although demographic variables like mean age in the groups was significantly different, use of an inpatient sample for study purposes may not accurately reflect the prevalence of BD and MetS in adolescent patients in the community. Most patients were prescribed and taking psychotropic medication prior to admission which may confound the association between $\mathrm{BD}$ and MetS. Considering the role of psychotropics in treatment of BD and effect upon MetS, detailed retrospective data was warranted, but was not available for this 
study. Another overlapping and limiting aspects were the high percentage of comorbid conduct disorder and cannabis use disorder in patient population. As literature suggests the strong interlink of $\mathrm{BD}$ with conduct disorder [58-60] and cannabis use disorder [61,62], thorough studies are needed in such BD population by excluding the comorbidities. A recent study reported the fluctuations in the discharge medications dosing and length of stay in adult BD population using cannabis and synthetic cannabis [63]. With a dearth of such studies in young BD population and increased prevalence of synthetic cannabis use in the community [64-66], it is crucial to integrate this factor in adolescent BD patients for further insight.

The reference group data used for this study is from the NHANES 1999-2000 report and a 2004 descriptive study [67]. To address the timeline difference between the data collected from the study and reference groups, we compared the prevalence of MetS in same age group from 2003 to 2011 , which was reported to be $2.9 \%$ and $5.6 \%$ for younger and older age children and adolescent groups, respectively [68]. In contrast, mean weight, waist circumference, and BMI in adults has noticed to be increased over time [69]. It is safe to assume that prevalence of MetS in the young population did not drastically increase over time, otherwise it would have convoluted the impact of BD on MetS. All significant covariates from the NHANES were unable to be obtained which significantly restricts our ability to understand the clinical depth in $\mathrm{BD}$ and MetS. Our study sample was distorted by a higher frequency of BD-NOS, compared to BD-I or BD-II. The younger age population has high incidence of BD-NOS [70], with a conversion rate of $30-50 \%$ from BD-NOS to BD-I or BD-II later on in life [71,72]. The inpatient setting from which the study sample was derived is focused on acute stabilization and length of stays are relatively short. This may lead to difficulties in clinically differentiating BD-I and BD-II. In such a limited setting, with lack of in-depth historical information and a short window of clinical monitoring, the assessing psychiatrist might have preferred a discharge diagnosis of BD-NOS in light of insufficient data for BD-I or BD-II diagnoses. Adequate follow-up of this cohort and subsequent comparison to baseline data could better elucidate this slant in discharge diagnosis.

The selection of the appropriate MetS-defining criteria for this study was another substantial challenge as various criteria are recognized. The World Health Organization (WHO) criteria (1998) has insulin resistance as an absolute requirement [73], the European Group for the Study of Insulin Resistance (EGIR) deems hyperinsulinemia compulsory [74], and the International Diabetes Foundation (IDF) mandates obesity as a requirement for MetS diagnosis [75]. In contrast to these differing defining criteria, NCEP ATP-III does not necessitate any specific criteria as an absolute requirement for MetS diagnosis. For simplicity, NCEP criteria were selected and BMI was used as a proxy to waist circumference which limits our scope of obesity as a MetS component.

Compared to the general adolescent population, the prevalence of metabolic abnormalities in child and adolescents with BD found to be significantly higher. These findings support the notion of amplified risk of metabolic disturbances at an early age in patients diagnosed with BD. Keeping in mind the pubertal hormonal changes and its influence on several physiological changes [76]; such as body fat changes [77], increased leptin resistance [78], adiponectin and resistin fluctuations etc. [79], it is pertinent to incorporate the notion of age while assessing BD and MetS spectrum in young population. Majority of studies in the past were focused primarily on adults; as opposed to adolescent populations with BD. It is noteworthy that metabolic disturbances within the child and adolescent population presents with an array of additional issues; that are distinct from the adult population, raises unique concerns especially future quality of life. Furthermore, heterogeneity in MetS is observed in sex-based comparison in adult population $[80,81]$. Such data is conflicting in children and adolescent population, with some reporting higher prevalence in males and in Hispanic ethnicity $[76,82,83]$, thus demanding a better grasp of the pathophysiology of MetS and its influence on BD.

This study recognizes metabolic disturbances in young patients diagnosed with $\mathrm{BD}$ to be a significant problem. It is essential to understand the effects of abnormal metabolic factors in early-onset BD; to allow the development of an improved patient-centered approach; to embrace preventive treatment, and thus to diminish morbidity and mortality associated with $\mathrm{BD}$ and metabolic abnormalities.

\section{- CDC Disclaimer}

The findings and conclusions in this paper are those of the author(s) and do not necessarily represent the views of 
the Research Data Center, the National Center for Health Statistics, or the Centers for Disease Control and Prevention.

\section{Acknowledgments}

We would like to thank all the research personnel at HCPC and department of Psychiatry for helping in this and every endeavor.

\section{Conflicts of Interest}

No potential conflict of interest relevant to this article was reported.

\section{Author Contributions}

Hanjing Wu, Teresa A. Pigott, and Jair C. Soares helped in conceptualization, Hanjing Wu and Teresa A. Pigott helped in data acquisition, formal analysis was performed by Hanjing $\mathrm{Wu}$, original draft's writing was done by Satyajit Mohite, review and edits were provided by Shiva Sharma, Hanjing Wu, Luca Lavagnino, Christian P. Zeni, Terrence T. Currie, Jair C. Soares, Teresa A. Pigott.

\section{ORCID}

Satyajit Mohite https://orcid.org/0000-0002-2873-3025 Hanjing Wu https://orcid.org/0000-0003-1208-8516 Shiva Sharma https://orcid.org/0000-0002-3270-9087 Luca Lavagnino https://orcid.org/0000-0003-1377-6871

Cristian P. Zeni https://orcid.org/0000-0001-9810-3929

Terrence T. Currie https://orcid.org/0000-0003-2562-5931 Jair C. Soares https://orcid.org/0000-0002-5466-5628 Teresa A. Pigott https://orcid.org/0000-0001-7608-9273

\section{REFERENCES}

1. Walther A, Penz M, ljacic D, Rice TR. Bipolar spectrum disorders in male youth: the interplay between symptom severity, inflammation, steroid secretion, and body composition. Front Psychiatry 2017;8:207.

2. Van Meter AR, Moreira AL, Youngstrom EA. Meta-analysis of epidemiologic studies of pediatric bipolar disorder. J Clin Psychiatry 2011;72:1250-1256.

3. Merikangas KR, He JP, Burstein M, Swanson SA, Avenevoli S, Cui $\mathrm{L}$, et al. Lifetime prevalence of mental disorders in U.S. adolescents: results from the National Comorbidity Survey Replication--Adolescent Supplement (NCS-A). I Am Acad Child Adolesc Psychiatry 2010;49:980-989.

4. Faedda GL, Baldessarini RJ, Glovinsky IP, Austin NB. Pediatric bipolar disorder: phenomenology and course of illness. Bipolar
Disord 2004;6:305-313.

5. El-Badri SM, Ashton CH, Moore PB, Marsh VR, Ferrier IN. Electrophysiological and cognitive function in young euthymic patients with bipolar affective disorder. Bipolar Disord 2001;3:79-87.

6. Pavuluri MN, Schenkel LS, Aryal S, Harral EM, Hill SK, Herbener ES, et al. Neurocognitive function in unmedicated manic and medicated euthymic pediatric bipolar patients. Am J Psychiatry 2006; 163:286-293.

7. Perlis RH, Miyahara S, Marangell LB, Wisniewski SR, Ostacher M, DelBello MP, et al.; STEP-BD Investigators. Long-term implications of early onset in bipolar disorder: data from the first 1000 participants in the systematic treatment enhancement program for bipolar disorder (STEP-BD). Biol Psychiatry 2004;55:875-881.

8. Cook S, Weitzman M, Auinger P, Nguyen M, Dietz WH. Prevalence of a metabolic syndrome phenotype in adolescents: findings from the third National Health and Nutrition Examination Survey, 1988-1994. Arch Pediatr Adolesc Med 2003;157:821-827.

9. Grover S, Malhotra N, Chakrabarti S, Kulhara P. Metabolic syndrome in bipolar disorders. Indian J Psychol Med 2012;34: 110-118.

10. Mclntyre RS, Danilewitz M, Liauw SS, Kemp DE, Nguyen HT, Kahn LS, et al. Bipolar disorder and metabolic syndrome: an international perspective. J Affect Disord 2010;126:366-387.

11. Vancampfort D, Vansteelandt K, Correll CU, Mitchell AJ, De Herdt A, Sienaert P, et al. Metabolic syndrome and metabolic abnormalities in bipolar disorder: a meta-analysis of prevalence rates and moderators. Am J Psychiatry 2013;170:265274.

12. Goldstein BI, Blanco C, He JP, Merikangas K. Correlates of overweight and obesity among adolescents with bipolar disorder in the National Comorbidity Survey-Adolescent Supplement (NCS-A). J Am Acad Child Adolesc Psychiatry 2016;55: 1020-1026.

13. Taylor V, MacQueen G. Associations between bipolar disorder and metabolic syndrome: a review. J Clin Psychiatry 2006;67:1034-1041.

14. Fagiolini A, Chengappa KN, Soreca I, Chang J. Bipolar disorder and the metabolic syndrome: causal factors, psychiatric outcomes and economic burden. CNS Drugs 2008;22:655669.

15. Maciukiewicz M, Dmitrzak-Weglarz M, Pawlak J, Leszczynska-Rodziewicz A, Zaremba D, Skibinska M, et al. Analysis of genetic association and epistasis interactions between circadian clock genes and symptom dimensions of bipolar affective disorder. Chronobiol Int 2014;31:770-778.

16. Ellingrod VL, Taylor SF, Dalack G, Grove TB, Bly MJ, Brook $\mathrm{RD}$, et al. Risk factors associated with metabolic syndrome in bipolar and schizophrenia subjects treated with antipsychotics: the role of folate pharmacogenetics. J Clin Psychopharmacol 2012;32:261-265. 
17. Mansur RB, Brietzke E, McIntyre RS. Is there a "metabolicmood syndrome"? A review of the relationship between obesity and mood disorders. Neurosci Biobehav Rev 2015;52:89104.

18. Avila C, Holloway AC, Hahn MK, Morrison KM, Restivo M, Anglin $\mathrm{R}$, et al. An overview of links between obesity and mental health. Curr Obes Rep 2015;4:303-310.

19. Jerrell JM, McIntyre RS, Tripathi A. A cohort study of the prevalence and impact of comorbid medical conditions in pediatric bipolar disorder. J Clin Psychiatry 2010;71:1518-1525.

20. Rankin SM, Conroy DM, Williams TJ. Eotaxin and eosinophil recruitment: implications for human disease. Mol Med Today 2000;6:20-27.

21. Moreira MA, Tilbery CP, Monteiro LP, Teixeira MM, Teixeira $\mathrm{AL}$. Effect of the treatment with methylprednisolone on the cerebrospinal fluid and serum levels of CCL2 and CXCL10 chemokines in patients with active multiple sclerosis. Acta Neurol Scand 2006;114:109-113.

22. Teruya-Feldstein J, Jaffe ES, Burd PR, Kingma DW, Setsuda JE, Tosato G. Differential chemokine expression in tissues involved by Hodgkin's disease: direct correlation of eotaxin expression and tissue eosinophilia. Blood 1999;93:2463-2470.

23. National Cholesterol Education Program (NCEP) Expert Panel on Detection, Evaluation, and Treatment of High Blood Cholesterol in Adults (Adult Treatment Panel III). Third report of the National Cholesterol Education Program (NCEP) Expert Panel on Detection, Evaluation, and Treatment of High Blood Cholesterol in Adults (Adult Treatment Panel III) final report. Circulation 2002;106:3143-3421.

24. Cheal KL, Abbasi F, Lamendola C, McLaughlin T, Reaven GM, Ford ES. Relationship to insulin resistance of the adult treatment panel III diagnostic criteria for identification of the metabolic syndrome. Diabetes 2004;53:1195-1200.

25. de Ferranti SD, Gauvreau K, Ludwig DS, Neufeld EJ, Newburger JW, Rifai N. Prevalence of the metabolic syndrome in American adolescents: findings from the Third National Health and Nutrition Examination Survey. Circulation 2004;110:24942497.

26. Drexhage RC, Knijff EM, Padmos RC, Heul-Nieuwenhuijzen Lv, Beumer W, Versnel MA, et al. The mononuclear phagocyte system and its cytokine inflammatory networks in schizophrenia and bipolar disorder. Expert Rev Neurother 2010; 10:59-76.

27. United States Department of Health and Human Services, Centers for Disease Control and Prevention, National Center for Health Statistics. National Health and Nutrition Examination Survey (NHANES), 1999-2000 (ICPSR 25501) [Internet]. Ann Arbor: Inter-university Consortium for Political and Social Research (ICPSR) [(updated 2012 Feb 22;) cited at 2018 Nov 27]. Available from: https://www.icpsr.umich.edu/icpsrweb/NACDA studies/25501/datadocumentation.

28. IBM Corporation. IBM SPSS statistics base 20. Armonk, NY:IBM Co.;2011
29. Fagiolini A, Frank E, Scott JA, Turkin S, Kupfer DJ. Metabolic syndrome in bipolar disorder: findings from the Bipolar Disorder Center for Pennsy/vanians. Bipolar Disord 2005;7: 424-430.

30. Vancampfort D, Stubbs B, Mitchell AJ, De Hert M, Wampers $\mathrm{M}, \mathrm{Ward} \mathrm{PB}$, et al. Risk of metabolic syndrome and its components in people with schizophrenia and related psychotic disorders, bipolar disorder and major depressive disorder: a systematic review and meta-analysis. World Psychiatry 2015;14: 339-347.

31. Goldstein BI, Birmaher B, Axelson DA, Goldstein TR, EspositoSmythers C, Strober MA, et al. Preliminary findings regarding overweight and obesity in pediatric bipolar disorder. J Clin Psychiatry 2008;69:1953-1959.

32. Naiberg MR, Newton DF, Collins JE, Dickstein DP, Bowie CR, Goldstein BI. Elevated triglycerides are associated with decreased executive function among adolescents with bipolar disorder. Acta Psychiatr Scand 2016;134:241-248.

33. Sundvall J, Laatikainen T, Hakala S, Leiviskä J, Alfthan G. Systematic error of serum trig/yceride measurements during three decades and the effect of fasting on serum triglycerides in population studies. Clin Chim Acta 2008;397:55-59.

34. Lee WY, Jung CH, Park JS, Rhee EJ, Kim SW. Effects of smoking, alcohol, exercise, education, and family history on the metabolic syndrome as defined by the ATP III. Diabetes Res Clin Pract 2005;67:70-77.

35. Liese AD, Mayer-Davis EJ, Tyroler HA, Davis CE, Keil U, Schmidt MI, et al. Familial components of the multiple metabolic syndrome: the ARIC study. Diabetologia 1997;40:963970.

36. Barzin M, Hosseinpanah F, Saber H, Sarbakhsh P, Nakhoda K, Azizi F. Gender differences time trends for metabolic syndrome and its components among Tehranian children and adolescents. Cholesterol 2012;2012:804643.

37. Goldstein BI, Collinger KA, Lotrich F, Marsland AL, Gill MK, Axelson DA, et al. Preliminary findings regarding proinflammatory markers and brain-derived neurotrophic factor among adolescents with bipolar spectrum disorders. J Child Adolesc Psychopharmacol 2011;21:479-484.

38. Goldstein BI, Lotrich F, Axelson DA, Gill MK, Hower H, Goldstein TR, et al. Inflammatory markers among adolescents and young adults with bipolar spectrum disorders. J Clin Psychiatry 2015;76:1556-1563.

39. McElroy SL, Frye MA, Hellemann G, Altshuler L, Leverich GS, Suppes T, et al. Prevalence and correlates of eating disorders in 875 patients with bipolar disorder. I Affect Disord 2011; 128:191-198.

40. Wildes JE, Marcus MD, Fagiolini A. Prevalence and correlates of eating disorder co-morbidity in patients with bipolar disorder. Psychiatry Res 2008; 161:51-58.

41. Martin K, Woo J, Timmins V, Collins J, Islam A, Newton D, et al. Binge eating and emotional eating behaviors among adolescents and young adults with bipolar disorder. I Affect 
Disord 2016;195:88-95.

42. Keck PE, McElroy SL. Bipolar disorder, obesity, and pharmacotherapy-associated weight gain. J Clin Psychiatry 2003;64: 1426-1435.

43. Gonzalo JA, Lloyd CM, Kremer L, Finger E, Martinez-A C, Siegelman $\mathrm{MH}$, et al. Eosinophil recruitment to the lung in a murine model of allergic inflammation. The role of $T$ cells, chemokines, and adhesion receptors. J Clin Invest 1996;98: 2332-2345.

44. Vasudevan AR, Wu H, Xydakis AM, Jones PH, Smith EO, Sweeney JF, et al. Eotaxin and obesity. J Clin Endocrinol Metab 2006;91:256-261.

45. Mattoli S, Stacey MA, Sun G, Bellini A, Marini M. Eotaxin expression and eosinophilic inflammation in asthma. Biochem Biophys Res Commun 1997;236:299-301.

46. Kitaura M, Nakajima T, Imai T, Harada S, Combadiere C, Tiffany $\mathrm{HL}$, et al. Molecular cloning of human eotaxin, an eosinophil-selective CC chemokine, and identification of a specific eosinophil eotaxin receptor, CC chemokine receptor 3. J Biol Chem 1996;271:7725-7730.

47. Patel NC, Delbello MP, Bryan HS, Adler CM, Kowatch RA, Stanford K, et al. Open-label lithium for the treatment of adolescents with bipolar depression. I Am Acad Child Adolesc Psychiatry 2006;45:289-297.

48. Blanchard C, Wang N, Stringer KF, Mishra A, Fulkerson PC, Abonia JP, et al. Eotaxin-3 and a uniquely conserved gene-expression profile in eosinophilic esophagitis. J Clin Invest 2006; 116:536-547.

49. McElroy SL, Keck PE Jr. Obesity in bipolar disorder: an overview. Curr Psychiatry Rep 2012;14:650-658.

50. Correll CU. Weight gain and metabolic effects of mood stabilizers and antipsychotics in pediatric bipolar disorder: a systematic review and pooled analysis of short-term trials. J Am Acad Child Adolesc Psychiatry 2007;46:687-700.

51. Almandil NB, Liu Y, Murray ML, Besag FM, Aitchison KJ, Wong IC. Weight gain and other metabolic adverse effects associated with atypical antipsychotic treatment of children and adolescents: a systematic review and meta-analysis. Paediatr Drugs 2013;15:139-150.

52. Fraguas D, Correll CU, Merchán-Naranjo J, Rapado-Castro M, Parellada M, Moreno C, et al. Efficacy and safety of second-generation antipsychotics in children and adolescents with psychotic and bipolar spectrum disorders: comprehensive review of prospective head-to-head and placebo-controlled comparisons. Eur Neuropsychopharmacol 2011;21: 621-645.

53. De Hert M, Dobbelaere M, Sheridan EM, Cohen D, Correll CU. Metabolic and endocrine adverse effects of second-generation antipsychotics in children and adolescents: a systematic review of randomized, placebo controlled trials and guidelines for clinical practice. Eur Psychiatry 2011;26:144158.

54. Vitiello B, Correll C, van Zwieten-Boot B, Zuddas A, Parellada
M, Arango C. Antipsychotics in children and adolescents: increasing use, evidence for efficacy and safety concerns. Eur Neuropsychopharmacol 2009;19:629-635.

55. Leonardi A, Jose PJ, Zhan H, Calder VL. Tear and mucus eotaxin-1 and eotaxin-2 in allergic keratoconjunctivitis. Ophthalmology 2003;110:487-492.

56. Ben Amor L. Antipsychotics in pediatric and adolescent patients: a review of comparative safety data. J Affect Disord 2012;138 Suppl:S22-S3O.

57. Gálvez JF, Sanches M, Bauer IE, Sharma AN, Hamilton J, Mwangi B, et al. Premorbid obesity and metabolic disturbances as promising clinical targets for the prevention and early screening of bipolar disorder. Med Hypotheses 2015;84:285293.

58. Kovacs M, Pollock M. Bipolar disorder and comorbid conduct disorder in childhood and adolescence. J Am Acad Child Adolesc Psychiatry 1995;34:715-723.

59. Geller B, Luby J. Child and adolescent bipolar disorder: a review of the past 10 years. J Am Acad Child Adolesc Psychiatry 1997; 36:1168-1176.

60. Chen MH, Su TP, Chen YS, Hsu JW, Huang KL, Chang WH, et al. Higher risk of developing mood disorders among adolescents with comorbidity of attention deficit hyperactivity disorder and disruptive behavior disorder: a nationwide prospective study. J Psychiatr Res 2013;47:1019-1023.

61. Duffy A, Horrocks J, Milin R, Doucette S, Persson G, Grof P. Adolescent substance use disorder during the early stages of bipolar disorder: a prospective high-risk study. J Affect Disord 2012;142:57-64.

62. Bitter SM, Adler CM, Eliassen JC, Weber WA, Welge JA, Burciaga J, et al. Neurofunctional changes in adolescent cannabis users with and without bipolar disorder. Addiction 2014;109:1901-1909.

63. Deng H, Desai PV, Mohite S, Okusaga OO, Zhang XY, Nielsen DA, et al. Hospital stay in synthetic cannabinoid users with bipolar disorder, schizophrenia, or other psychotic disorders compared with cannabis users. J Stud Alcohol Drugs 2019;80:230-235.

64. Bonar EE, Ashrafioun L, Ilgen MA. Synthetic cannabinoid use among patients in residential substance use disorder treatment: prevalence, motives, and correlates. Drug Alcohol Depend 2014;143:268-271.

65. Mehta JJ, Mahendran AK, Bajaj RK, Doshi AR. Myocardial ischemia with cannabinoid use in an adolescent. Cureus 2017; 9:e1899.

66. Castellanos D, Gralnik LM. Synthetic cannabinoids 2015: an update for pediatricians in clinical practice. World J Clin Pediatr 2016;5:16-24.

67. Ransohoff RM. The chemokine system in neuroinflammation: an update. J Infect Dis 2002;186 Suppl 2:S152-S156.

68. Teixeira AL Jr, Cardoso F, Souza AL, Teixeira MM. Increased serum concentrations of monokine induced by interferongamma/CXCL9 and interferon-gamma-inducible protein 10/ 
CXCL-10 in Sydenham's chorea patients. I Neuroimmunol 2004; 150:157-162.

69. Teixeira AL, Reis HJ, Nicolato R, Brito-Melo G, Correa H, Teixeira MM, et al. Increased serum levels of CCL11/eotaxin in schizophrenia. Prog Neuropsychopharmacol Biol Psychiatry 2008;32:710-714.

70. Biber K, Zuurman MW, Dijkstra IM, Boddeke HW. Chemokines in the brain: neuroimmunology and beyond. Curr Opin Pharmacol 2002;2:63-68.

71. Müller N, Weidinger E, Leitner B, Schwarz MJ. The role of inflammation in schizophrenia. Front Neurosci 2015;9:372.

72. Kirkpatrick B, Miller BJ. Inflammation and schizophrenia. Schizophr Bull 2013;39:1174-1179.

73. Alberti KG, Zimmet PZ. Definition, diagnosis and classification of diabetes mellitus and its complications. Part 1: diagnosis and classification of diabetes mellitus provisional report of a WHO consultation. Diabet Med 1998;15:539-553.

74. Balkau B, Charles MA. Comment on the provisional report from the WHO consultation. European Group for the Study of Insulin Resistance (EGIR). Diabet Med 1999;16:442-443.

75. Zimmet P, Magliano D, Matsuzawa Y, Alberti G, Shaw J. The metabolic syndrome: a global public health problem and a new definition. J Atheroscler Thromb 2005;12:295-300.

76. Jessup A, Harrell JS. The metabolic syndrome: look for it in children and adolescents, too! Clin Diabetes 2005;23:26-32.

77. Asayama K, Hayashibe H, Dobashi K, Uchida N, Kawada Y, Nakazawa S. Relationships between biochemical abnormal- ities and anthropometric indices of overweight, adiposity and body fat distribution in Japanese elementary school children. Int J Obes Relat Metab Disord 1995;19:253-259.

78. Valle M, Gascón F, Martos R, Bermudo F, Ceballos P, Suanes A. Relationship between high plasma leptin concentrations and metabolic syndrome in obese pre-pubertal children. Int J Obes Relat Metab Disord 2003;27:13-18.

79. Boyraz M, Cekmez F, Karaoğlu A, Cinaz P, Durak M, Bideci A. Relationship of adipokines (adiponectin, resistin and RBP4) with metabolic syndrome components in pubertal obese children. Biomark Med 2013;7:423-428.

80. Pradhan AD. Sex differences in the metabolic syndrome: implications for cardiovascular health in women. Clin Chem 2014;60:44-52.

81. Regitz-Zagrosek V, Lehmkuhl E, Weickert MO. Gender differences in the metabolic syndrome and their role for cardiovascular disease. Clin Res Cardiol 2006;95:136-147.

82. Syme C, Abrahamowicz M, Leonard GT, Perron M, Pitiot A, Qiu X, et al. Intra-abdominal adiposity and individual components of the metabolic syndrome in adolescence: sex differences and underlying mechanisms. Arch Pediatr Adolesc Med 2008;162:453-461.

83. Gurka MJ, Ice CL, Sun SS, Deboer MD. A confirmatory factor analysis of the metabolic syndrome in adolescents: an examination of sex and racial/ethnic differences. Cardiovasc Diabetol 2012;11:128. 